\title{
Fenomenologia, Hipnose e Dor Crônica: Passos para Uma Compreensão Clínica
}

\section{Phenomenology, Hypnosis, and Chronic Pain: Steps for Clinical Understanding}

\section{Mauricio da Silva Neubern*}

Universidade de Brasília - UnB, Asa Norte, Brasília, Brasil

\begin{abstract}
RESUMO
O presente trabalho propõe, por meio das noções fenomenológicas de autoimagem e esquema corporal, uma possibilidade explicativa e clínica para as relações entre hipnose e dores crônicas. Partindo de uma crítica ao teor médico e nomotético das pesquisas contemporâneas, onde pouco se concebem as questões clínicas, o trabalho enfatiza, como método, um estudo de caso de uma pessoa que se submeteu a um processo hipnoterápico e cujas dores crônicas estavam configuradas tanto em termos de esquema corporal, como de auto-imagem. O trabalho é concluído destacando que não existe uma relação linear entre tais noções e que as dores crônicas se configuram de forma singular em cada pessoa, o que exige uma atitude clínica e qualitativa para acessá-las e compreendê-las, tanto em termos de noções fenomenológicas clássicas, como tempo, espaço e materialidade vividos, como de dimensões sócio-culturais que contribuem para a produção de sentido das experiências cotidianas dos sujeitos.
\end{abstract}

Palavras-chave: hipnose, dor, auto-imagem, corpo, fenomenologia.

\begin{abstract}
This paper proposes phenomenological notions of self-image and body schema as an explicative and clinical possibility for the relationship between hypnosis and chronic pain. It begins with a critique of the medical and nomothetic approach taken by contemporary research that does not usually address clinical issues, and then addresses a case study where a person suffering from chronic pain related both body schema and self-image is submitted to hypnotherapy. The study concludes that there is no linear relationship between such notions and that chronic pain is uniquely configured to each person. This requires a clinical and qualitative approach to access and understand chronic pain, both in terms of classic phenomenological notions of time, space, and material experiences, as well as socio-cultural dimensions that contribute to producing feelings related to the daily experiences of the subjects.
\end{abstract}

Keywords: hypnosis, pain, self-image, body, phenomenology.

\section{I ntrodução}


A despeito da longa tradição de aplicação clínica da hipnose para dores crônicas (Neubern, 2010a; Stengers, 2002), as pesquisas contemporâneas obedecem a uma perspectiva médica e estatística que pouco contemplam a dimensão clínica. O tratamento de problemas específicos, a discussão sobre sugestionabilidade, a avaliação de modelos de intervenção e as respostas de certos grupos populacionais são os focos dominantes em tais estudos (Jensen, 2010; Patterson, 2006), cuja perspectiva central fundamenta-se na lógica linear de avaliação (geralmente por escalas e questionários) de amostras significativas de pessoas que se submeteram a intervenções hipnóticas. Malgrado a relevância de tais estudos, sobretudo no tocante à generalidade de grandes grupos, existe uma lacuna nada desprezível em termos clínicos, como no que concerne aos processos relacionais aí presentes, à produção de sentidos associados às dores crônicas e aos tipos de mudança que a hipnose pode proporcionar às mesmas. O que a hipnose pode desencadear na experiência de tais pessoas, em que níveis de sua organização subjetiva e corporal ela atua em termos de dores crônicas, como as mudanças por ela proporcionadas ocorrem e se mantêm são questões de grande relevância clínica que acorrem cotidianamente aos profissionais e pesquisadores da área que, no entanto, não são abordadas pelas pesquisas atuais.

Tais pesquisas, imbuídas do pensamento médico hegemônico, distanciam a compreensão do tema de uma perspectiva antropológica, tanto para a dor crônica, como quanto à hipnose (Neubern, 2009a). De um modo geral, a experiência de dor vivida por um paciente acaba sendo descontextualizada de suas raízes sociais e culturais, do jogo complexo de subjetivação de sua vida cotidiana e transformada numa entidade isolada, acessível apenas ao saber médico e seu arsenal de técnicas e procedimentos. Concebida sob a ótica da dicotomia mente-corpo, a dor se transforma em algo restrito ao corpo onde, no máximo, podem ocorrer algumas relações longínquas com a psique ou com a vida social do paciente, que nada pode fazer quanto à mesma, a não ser acatar e obedecer o que o medico vier a lhe propor. Já a hipnose, desvencilhada de toda a herança clínica que Ihe caracterizou suas origens (Stengers, 2002), torna-se uma técnica unilateral (na qual o especialista prescreve sugestões diretas) e voltada para a eliminação pontual de sintomas. A construção da mudança, em termos processuais, o nível de alcance da técnica, sua capacidade de contemplação das necessidades do paciente, assim como a formação do vínculo e do contexto são temas que, apesar da importância fundamental, em nada parecem despertar o interesse de tais pesquisadores. Nesse sentido, é possível conceber que a visão restrita de tais perspectivas, que excluiu importantes zonas de sentido do campo de pesquisa, contribuam para uma compreensão empobrecida do mesmo e ainda para uma abordagem 
insuficiente das necessidades vivenciadas pelos pacientes acometidos por dores crônicas.

Entretanto, apesar das perspectivas fenomenológicas ainda não se constituírem como propostas de pesquisa para a relação entre hipnose e dores crônicas, elas possuem uma potencialidade promissora em termos explicativos e clínicos, principalmente por resgatar a dimensão humana que constitui tais processos. Rompendo com a dicotomia mente-corpo, numa ótica em que o corpo se torna o principal território existencial do sujeito (Merleau-Ponty, 2008), é possível cogitar a dor crônica como uma experiência que ganha sentido no mundo vivido do paciente, que é perpassado por referenciais de espacialidade, temporalidade, materialidade, causalidade e relações com os outros (Ellenberger, 2004). Assim, a dor persistente e cruel de um paciente oncológico, por exemplo, pode limitá-lo em seus círculos de movimentação pelo mundo, restringindo seu espaço de ação; pode parecer interminável quando o ataca e levá-lo a profundas reflexões existenciais sobre seu porvir; pode envolvê-lo numa vivência de peso que exaure suas forças, como se tudo em seu mundo fosse constituído de chumbo; como ainda pode levá-lo a um distanciamento considerável quanto às demais pessoas, de modo a sentir uma profunda sensação de abandono, mesmo que, fisicamente, estas se encontrem próximas. Esse conjunto de referenciais, que atuam em conjunto na vivência de uma pessoa, longe de remeterem a uma perspectiva causalista, proporcionam a configuração ou forma ${ }^{1}$ de diversos sentidos subjetivos de suas dores crônicas, de modo a situá-la em sua vida cotidiana, perpassada por suas crenças, heranças familiares, círculos de relações, inserção no trabalho e na vida comunitária em geral. Desse modo, um procedimento terapêutico como a hipnose (Erickson \& Rossi, 1979) pode ser de grande relevância ao atuar na reconfiguração de tais sentidos, de modo a modificar a experiência de dor crônica.

No entanto, a fenomenologia oferece ainda duas noções de considerável importância que permitem um aprofundamento significativo na compreensão clínica dessa relação. A princípio, a noção de esquema corporal, inicialmente desenvolvida por MerleauPonty (2008), refere-se a um conjunto de processos que integram as possibilidades de postura e movimento de uma pessoa. Integrando diferentes níveis de experiência corpórea ${ }^{2}$ (Merleau-Ponty, 2005), os esquemas articulam diferentes partes do corpo vivido, com suas diversificadas funções, numa totalidade que permite a organização de movimentos e posturas para situações cotidianas, como o caminhar, como para situações mais específicas e refinadas, como as ações do esporte e da arte (Gallagher, 2005). Essa totalidade implica tanto numa virtualidade de linhas de percurso para um conjunto de movimentos possíveis, como nos sentidos que tais movimentos adquirem para o corpo em seu trânsito existencial pelo mundo. Nesse 
sentido, pode-se cogitar que as dores crônicas reconfigurem os esquemas corporais de uma pessoa, alterando a virtualidade de seus movimentos, como os sentidos de tais movimentos em termos de sua corporeidade. A impossibilidade total ou parcial de execução de certos movimentos, situação comum em pessoas com dores crônicas, passa pela inibição de alguns elementos de seus sistemas que altera a configuração mais ampla da totalidade do esquema. Logo, é possível considerar que a eficácia da hipnose em tais circunstâncias se deva a sua capacidade de reativar elementos do esquema corporal que se encontravam na condição de fundo em termos do mundo vivido dos sujeitos (talvez inibidos ou esquecidos) para colocá-los na condição de figura, onde passam a alterar novamente a totalidade do conjunto, flexibilizando e re-organizando de nova forma as configurações das dores crônicas.

Outra concepção importante, que vem ao encontro de diferentes estudos clínicos no assunto (Erickson, 1985; Haley; 1985, Neubern, 2009b) é a de auto-imagem (Gallagher, 2005; Gallagher \& Zahavi, 2008), que implica no conjunto de percepções, sentidos subjetivos e atitudes do sujeito sobre si mesmo. Também se organizando numa perspectiva configuracional, a auto-imagem situa o sujeito frente a si e ao mundo, sendo perpassada por diferentes registros sociais e culturais oriundos de distintos momentos de inserção social do sujeito, podendo envolver questões relativas ao papel familiar, gênero, religião, economia, pertencimento étnico, geográfico, social e cultural, dentre outros. Não raro, a dor crônica apresenta importantes ramificações nesta dimensão, uma vez que pode alterar sua posição em termos econômicos e familiares (situando-o como dependente ao invés de provedor), produzir sentidos de fracasso diante de exigências de performance profissional, ou de pecado face a suas crenças religiosas (a dor como punição divina). Desse modo, a hipnose pode se mostrar como importante recurso terapêutico nessa dimensão enquanto processo de reorganização da experiência em termos de figura e fundo, como acima destacado, como ainda enquanto forma de redefinição da percepção dos pacientes face à emergência de novas experiências que proporcionam. Em outras palavras, a hipnose, em tal dimensão, não se restringe a um procedimento catártico, uma vez que abrange a criação de um contexto seguro que ofereça continência, organização e possibilidades de produção de sentidos diante dos novos arranjos experienciais entre figura e fundo.

Desse modo, o presente trabalho procura oferecer, por meio das noções fenomenológicas de esquema corporal e auto-imagem, uma possibilidade explicativa e clínica para as relações entre hipnose e dores crônicas. Por meio de estudo de caso ${ }^{3}$, busca destacar como a hipnose atua em termos de esquema corporal, modificando a organização da totalidade de configurações de dores crônicas, de 
modo a flexibilizar a virtualidade dos movimentos e a produção de sentidos sobre o mesmo. Neste processo, a evocação de experiências implica na reorganização figura-fundo do mundo do sujeito de maneira a flexibilizar referenciais de tempo, espaço e materialidade vividos (Ellenberger, 2004). Também procura destacar como a hipnose atua no nível da auto-imagem, evocando experiências que proporcionam a ruptura com a produção de sentidos negativos quanto a si mesmo, voltados tanto para uma nova relação com a espacialidade (no caso, de pertencimento cultural), com sua história e, sobretudo, na relação com as outras pessoas.

\section{Roberto Ferreira, 65 anos}

Roberto Ferreira, advogado e empresário, casado e pai de quatro filhos, chegou ao serviço devido a fortes dores em diferentes partes do corpo. No geral, sentia consideráveis dores nos ombros e na junção entre o pescoço e o corpo e na altura da bacia, principalmente próximo à parte interna da coxa direita. Suas dores eram provenientes tanto de um atropelamento sofrido há mais de um ano, como de duas cirurgias para extração de tumores oncológicos, um na coxa outro na próstata, que haviam ocorrido há mais de três anos. Mergulhado em tal forma de vivência, no início do processo terapêutico, Roberto apresentava não apenas dores de grande intensidade nessas regiões do corpo, que lhe traziam diversas limitações, mas ainda momentos frequentes e sofridos de depressão e pânico, vez por outra acompanhados de ideações suicidas. Assim, embora se mostrasse simpático e colaborativo, uma de suas características mais típicas, o paciente apresentava um peso nada desprezível em suas expressões, sem demonstrar valorização de importantes conquistas familiares e profissionais. Desse modo, não parecia depositar esperanças nos tratamentos médico e fisioterápicos aos quais comparecia, mas com relação aos quais não demonstrava engajamento nem motivação de maneira que apenas os apelos da família faziam com que continuasse a frequentá-los.

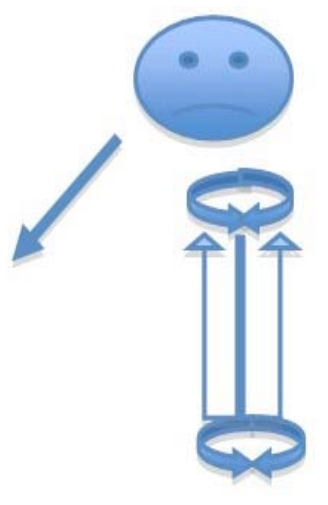


Figura 1. Representação das linhas virtuais do esquema corporal do paciente ao início da terapia. As setas circulares inferiores representam a limitação do campo de movimentação dos pés, enquanto as superiores, as limitações de movimentação dos ombros. Entre ambas, as setas laterais implicam a restrição do campo de movimento da coluna. A restrição do diâmetro das setas circulares remete à pouca abrangência de rotação da coluna e à precariedade do equilíbrio. Já a seta diagonal saindo da face indica a considerável restrição do foco de visão disponível ao paciente.

Do ponto de vista do esquema corporal, tal como destacado na figura 1 , as dores já cronificadas de Roberto pareciam se organizar de modo complexo. A cabeça parecia encontrar muitas dificuldades em seus diferentes movimentos de rotação. Seus braços ficavam sempre rígidos e próximos ao corpo, no intuito de buscar manter o equilíbrio já comprometido pelas dores na coluna. Era-lhe difícil mover o corpo, principalmente a coluna, além dos limites da rotação vertical (fig. 1) de maneira que seus movimentos pareciam sempre se voltar para duas reações que provinham de seu esquema corporal: o medo da queda e o temor de intensificação das dores já muito intensas. Tais formas de organização do esquema traziam duas grandes zonas de abrangência, que mereceram especial atenção no tratamento hipnoterápico. A primeira delas era relacionada a um conjunto de formas ou configurações (Merleau-Ponty, 2005) da região troncopescoço-cabeça na qual qualquer movimento parecia ameaçar o frágil equilíbrio já conquistado em torno de uma grande restrição de movimentos que o impediam tanto de relaxar o corpo, como de sentir a liberdade para poder olhar para onde desejasse. Esse conjunto de formas envolvia os músculos de modo a manter a cabeça ligeiramente voltada para a esquerda e para baixo de maneira a fazer com que o sujeito movesse o conjunto de uma só vez, sem permitir a relativa independência do ombro, do pescoço e da cabeça. Toda a potencialidade de movimentação e articulação dessas partes parecia ser contida pela rigidez de linhas de força da virtualidade do esquema que faziam o paciente fixar o olhar numa dada direção e manter todo o conjunto como refém desse ato. Além da dor que vez por outra expressava-se por um incômodo latejar, essas linhas de força eram acompanhadas por uma terrível sensação de peso e, caso o paciente se movimentasse além do permitido pela virtualidade desse novo esquema, surgia uma dor muito intensa e persistente, marcada por puxamentos, queimações e torções dos músculos.

Partindo-se da ideia na qual o esquema de uma parte implica o sujeito como um todo (Merleau-Ponty, 2008), a tirânica imposição desse esquema trazia consequências muito sofridas para Roberto. A relação com importantes focos de sua intencionalidade pelo mundo viam-se comprometidas, a começar pela restrição de seu foco visual que havia perdido as possibilidades anteriores de escolha e movimento. Assim, tanto a apreciação da paisagem, que Ihe dava muito prazer, pois havia se tornado um exímio fotógrafo, como a 
interação com as pessoas, dimensão afetiva muito importante de sua subjetivação, devido a sua afável sociabilidade, tornaram-se comprometidas, limitando relevantes fontes de prazer e produção de sentido, o que culminou com seu isolamento social. A cabeça paralisada e pesada sobre os ombros, em suma, abria espaço para uma produção de sentidos muito negativa sobre seu mundo, que o faziam se enclausurar cada vez mais em imaginações depressivos, com vozes, imagens e idéias que o levavam a pensar seriamente em desistir da vida.

Já no que se refere ao esquema que abrangia a coluna, as pernas e a bacia, a imposição das restrições pelas dores crônicas também se fazia notar de modo marcante. Ao caminhar, por exemplo, a bacia parecia acompanhar minuciosamente o movimento rígido dos ombros, de maneira a não produzir o ritmo de alternância, típico do caminhar comum, entre o ombro e a perna do lado contrário: Roberto projetava o ombro e a perna do lado direito e, em seguida, o ombro e a perna do lado esquerdo. Isso caracterizava uma perda da flexibilidade das linhas virtuais desse complexo esquema, nas quais a alternância permite o equilíbrio, a movimentação progressiva do caminhar e uma considerável economia energética. Entretanto, tais movimentos, para este paciente, não apenas eram muito cansativos e desgastantes, mas também implicavam numa amplitude muito restrita de rotação da coluna, no escasso alcance de seus passos e na precariedade de seu equilíbrio, que já havia Ihe faltado em algumas ocasiões de queda. Desse modo, tanto a rotação da coluna como o alcance circular de movimento para os pés (fig. 1) pareciam altamente limitados de maneira que atividades corriqueiras como caminhar, sentar-se, levantar-se da cama, tomar banho e fazer a higiene pessoal geralmente eram acompanhadas de muita dor, que repuxava e apertava seus músculos e nervos, fazendo com que necessitasse da ajuda de outras pessoas. Semelhantes experiências afiguravam-se para ele como uma crueldade do destino, pois o homem ativo e batalhador que sempre fora em sua vida, via-se agora impossibilitado de ficar ereto, manter a cabeça erguida, contemplar o mundo e se mover por ele, de modo a explorá-lo para tirar dele sustento e realização, sem contar o quase que completo comprometimento de sua autonomia face à necessidade de ser cuidado pelos outros. Essa dificuldade de mover-se e posicionar-se adquiriu para ele um sentido de limitação existencial, que o levava a uma perda de leveza de movimentação pelo mundo, como a uma terrível sensação de fracasso.

Por outro lado, sua auto-imagem também se mostrava comprometida, de maneira que o intenso sofrimento desse conjunto de limitações parecia atrair e colocar como figura no cenário de sua experiência uma série de processos e sentidos negativos fabricados ao longo de sua historia. Roberto havia sido criado na roça no interior 
do Piauí, sendo muito exigido pelos pais, inclusive com surras com varas de marmelo. A justificativa para tais métodos "educativos" se dava por ser ele o filho mais velho, que deveria cuidar dos outros e ajudar no sustento da família. Sua alfabetização só começaria aos 18 anos e até se tornar um advogado e empresário bem sucedido em Brasília, teria sofrido muitas dificuldades, passado por humilhações e privações de toda sorte. Ao mesmo tempo em que não valorizava todo seu potencial para conquistas tão impressionantes, Roberto facilmente se colocava em relações nas quais era explorado pelos outros. Tanto seus funcionários, como seus familiares cedo aprendiam a chantageá-lo para tirar proveito financeiro ou de outras ordens - situação que Ihe trazia muito sofrimento, mas contra a qual geralmente não sabia como se defender. Logo, não se sentindo capaz de estabelecer uma negociação franca e aberta com os outros, inclusive quanto a seus sentimentos, ele tanto evitava o confronto, como se utilizava do dinheiro como um veículo para obtenção da amizade e das atenções das pessoas, com relação às quais gostaria sempre de manter uma boa imagem. Mesmo que estivesse com a razão diante de uma situação injusta, como a exploração de um parente ou o roubo de um funcionário desonesto, a tomada de uma atitude para que defendesse seus interesses e seu patrimônio, caso fosse efetivada, seria ao custo de muito sofrimento.

Logo ao início da terapia chamou a atenção sua dificuldade em se encarar no espelho, de maneira a mostrar fortes reações emocionais, tremores e impossibilidade de fixação do olhar. Na conversação sobre o assunto, Roberto trouxe, seguidas vezes, o tema da vergonha que sentia sobre suas origens sertanejas: por ser nordestino; por ter vivido na pobreza; por só ter aprendido a ler e escrever quando era adulto; pelo formato de seu corpo e de sua cabeça. Tais experiências, vistas por ele como motivo de vergonha, colocavam-no numa condição inferior frente aos outros, de modo que, a principio, ao começar uma relação qualquer, seu lugar deveria ser abaixo dos das outras pessoas. Nesse sentido, suas inúmeras conquistas só eram percebidas como frutos de obrigação e cumprimento do dever, o que não abriria o menor espaço para sentimentos de orgulho e reconhecimento. Em meio semelhante cenário, onde as possibilidades e processos construtivos de sua subjetivação pareciam restritas e escondidas (fundo), o paciente encontrava o casamento inevitável entre as dores crônicas e a depressão, enfatizando o passado de forma negativo, o presente vivido sob peso, dor e sofrimento e o futuro, a bem dizer, praticamente bloqueado.

\section{Utilização da Hipnose}


As intervenções hipnóticas aqui utilizadas (Erickson, 1985; Erickson \& Rossi, 1979) possuem princípios de grande relevância para a abordagem de pessoas acometidas por dores crônicas e que podem ser sinteticamente destacadas. Em primeiro lugar, ao invés da típica prescrição ou ordem direta que caracterizou o advento da hipnose clássica (Neubern, 2009a), as sugestões são construídas no formato de histórias, metáforas ou explanações de modo a oferecerem uma ampla estrutura de significados (Lakoff \& Johnson, 2003) para o paciente que lhe possibilitam a reconstrução de diferentes configurações de sentido ligados às experiências de dor crônica e às temáticas a elas integradas. Como tal modo de sugestão tende a não mobilizar resistências, ou ao menos na intensidade das sugestões diretas, o paciente se sente convidado ou instigado a participar do processo, mobilizando suas próprias vivências, memórias, aprendizados a favor das mudanças possíveis implicadas nas sugestões. Em segundo lugar, tais sugestões sempre apontam para algum encaminhamento ou solução quanto aos problemas vividos, de maneira a conferir um direcionamento ao processo terapêutico no qual o sujeito se engaja ativamente. Portanto, elas não visam necessariamente o insight de conteúdos reprimidos no inconsciente, mas uma reconfiguração pragmática da experiência que, por vezes, não é acessada diretamente pelo sujeito em termos de tomada de consciência, mas trazem seus efeitos concretos na modificação do vivido da dor crônica e de suas temáticas cotidianas, como a vida conjugal, a relação com o dinheiro e o trabalho, a inserção na comunidade, dentre outros.

Em terceiro lugar, uma mesma estrutura de sugestões pode envolver uma considerável complexidade, uma vez que abarca diferentes técnicas hipnóticas que abrangem diversos níveis de experiência de dor crônica (Neubern, 2010b). Ao mesmo tempo em que as sugestões podem remeter o sujeito a vivenciar mais nitidamente as sensações, aprendizados e movimentos corporais, envolvendo assim as formas do esquema corporal, elas podem também colocá-lo frente a temas centrais de sua auto-imagem, como a relação com o outro e a qualidade do afeto endereçado a si mesmo. Dentro de cada momento ou sessão de uma estrutura maior (Lakoff \& J ohnson, 1999, 2003) o terapeuta pode aplicar técnicas hipnóticas específicas de maneira a contemplar objetivos mais ou menos pontuais ligados às complexas configurações de dores crônicas vividas pelos pacientes. A seguir encontram-se alguns exemplos de sugestões indiretas deste estudo de caso, cujo modelo foi utilizada ao longo do processo terapêutico de Roberto. Vale destacar que aqui são apresentadas apenas alguns trechos, pois, na prática, tais sugestões são muito mais longas.

Exemplo 1 (segunda sessão, primeiro mês de terapia) 
O terapeuta inicia a indução com a técnica da levitação de braço (Erickson, 1985) ${ }^{4}$. Em seguida, procede dessa forma (T):

"E você pode aproveitar e observar, sentir o que acontece com sua mão( ...) talvez ela fique diferente do resto do corpo, talvez você sinta nela um leve formigamento .... E enquanto uma parte sua observa o que ocorre com seu braço, outra escuta o que falo pra você. E uma criança pode aprender muitas coisas brincando. Brincar no rio, pular na água, secar-se ao sol, espichando-se (...) e ficar ali o tempo que quiser( ...) e sentir a água no corpo, mostrando-Ihe os limites do corpo, o frescor na pele ... e sentir o calor do sol, secando o corpo, relaxado( ...) e de um jeito muito prazeroso.... E o que vem pra você nesse momento, Roberto?" (R): "Eu estava na beira do rio, pescando com meus amiguinhos, minha mãe olhando de longe(...) agora estou secando no sol, sinto um calor muito bom..."

Nesse instante, ele se levanta e começa, mesmo em transe, a fazer movimentos circulares com os braços e o terapeuta acrescenta $(T)$ :

“E você pode aproveitar esse calor e deixá-lo circular pelo seu corpo $(. .$.$) e perceber o que ele pode fazer com cada região de$ seu corpo ( ...) e como ele faz com as fibras musculares( ...) que podem se soltar suavemente( ...) e o tipo de relaxamento que ele faz ..."

Este trecho é muito significativo por destacar pontos de grande importância para o processo deste paciente. A princípio é possível que a técnica de levitação do braço tenha desencadeado uma experiência corporal distinta da habitual, como analgesia, uma vez que o paciente se levantou e pôs-se a realizar movimentos muito mais soltos e amplos com relação às linhas virtuais típicas de seu esquema corporal. A sugestão contemplou ainda momentos felizes de sua infância, ricos em sensorialidade corporal, brincadeiras, socialização e um ponto muito importante: o cuidado da mãe que, até o momento, só havia aparecido em seus relatos como uma figura opressora e tirânica. Assim, ao focar no sensório o terapeuta aplicava a técnica da ancoragem (Neubern, 2010b) que permite a amplificação de uma experiência sensória capaz de contrapor às sensações desagradáveis provocadas pela dor crônica; ao trazer a dimensão lúdica, social e de cuidado, ele foca a atenção do paciente em experiências relevantes, alegres e positivas que também compõem seu mundo vivido, rompendo, em alguma medida, com a hegemonia negativista com a qual costumava relatar sua trajetória de vida. $E$, por fim, ao ancorar a experiência do calor, durante o transe, o paciente transpirou intensamente, o que trazia uma sensação 
marcante de aumento da temperatura na própria sala de atendimento. Segundo seu relato, essa dimensão do calor promoveu não apenas uma forte sensação de relaxamente e prazer, como há muito não experimentava, mas também uma vivência de se sentir acolhido naquele contexto, de que ali parecia ser o seu espaço de terapia. No geral, é possível conceber que esta única sessão abriu consideráveis perspectivas para o processo de Roberto, tanto por reduzir sua dor, trazer-Ihe de novo a possibilidade de se movimentar além da rigidez do esquema corporal, como de conectar-se com outras nuances de sua história e aceitar um novo espaço terapêutico.

Exemplo 2 (terceiro mês de terapia)

Nesta sugestão o terapeuta procedeu da seguinte forma:

“E você pode perceber, Roberto, como aquele menino pôde aprender tão rápido a negociar vacas e cabras (...) e levava as coisas da roça para trocar na feira e, mesmo com 18 anos, ele quis começar a aprender a ler e escrever e hoje lê vários livros (...) devora-os (...) e quem o observasse hoje lendo tantos livros não diria que ele aprendeu a ler tão tarde(...) e você pode comparar as roupas daquela criança da roça com os ternos do homem maduro de hoje (...) e se perguntar o que elas têm a ver? E fico me perguntando o que esse menino sabia tanto que levou esse adulto a frequentar ambientes 'chiques' e refinados e ser tão respeitado por pessoas importantes (...) eu gostaria muito de saber qual é o segredo deste menino pobre da roça ..."

Esse conjunto de sugestões traz à tona, novamente, a possibilidade de que o paciente se conectasse de outras maneiras com suas próprias experiências, no sentido de valorizá-las como conquistas. Há aqui uma tônica que acompanhou todo seu processo terapêutico: a valorização de suas raízes culturais associada a suas conquistas ao longo da vida. Tratava-se de um modo de oferecer alguma estrutura de sugestões que permitisse uma reorganização dos sentimentos de vergonha, muito comuns em sua auto-imagem. As sugestões, neste trecho, ainda foram apresentadas no sentido de redefinir a herança recebida de sua infância, como de seu nicho familiar e cultural: aquele menino não era uma simples vítima de injustiças ou um sertanejo ignorante, mas possuía um segredo que permitiu que Roberto pudesse ascender em muito em sua vida social e financeira. Tratava-se de um modo de oferecer, a partir de elementos trazidos por seus próprios relatos, uma forma de redefinir a importância de suas origens, com uma profunda capacidade de superar obstáculos e obter conquistas, apesar dos sofrimentos. 
Exemplo 3 (oitavo mês de terapia)

Neste trecho, o terapeuta traçou as seguintes sugestões:

“E você já aprendeu muitas coisas sobre o transe (...) que você pode caminhar e se movimentar, (...) ficar de pé e abrir os olhos $(. .$.$) e pedirei pra você que se prepara para uma coisa$ importante a fazer (...) que você se levante e fique de pé ... (ele assim o fez) ... e que olhe para aquele ponto (terapeuta aponta para a imagem do paciente no espelho) e observe essa pessoa, olhando-a nos olhos ... e sinta o que ela lhe transmite ..." (R): "Isso é muito difícil para mim. Não consigo olhar por muito tempo (...) mas vou tentar ..." (T): "Isso, você pode olhar e sentir o que ela lhe transmite." Algumas sessões depois, o terapeuta repete o procedimento e pede para que 0 paciente se sente de novo. Em seguida fala: "E você pode ver as pessoas importantes de sua vida (...) seus parentes, irmãos, amigos, filhos, esposa(...) e olhar no semblante de cada um deles e abraçá-los (...) e como você dizia, 'agradecer a Deus' por cada um deles (...) mas há uma pessoa chegando ali que você conhece muito bem, mas nem sempre olha pra ela(...) quem é Roberto?" (R) “Nossa, sou eu" (T): "Sim, é você. E vou lhe dizer uma coisa. Essa pessoa está há muito tempo esperando um abraço seu. Você já a abraçou? Então você pode ir até ela e abraçá-la."

Este momento foi seguido de muito choro, da parte do paciente, para quem foi o momento mais importante de seu processo terapêutico.

Algumas sessões após este momento, o paciente trouxe suas preocupações com a temática do dinheiro. O terapeuta, aproveitando o interesse do paciente por pesca, colocou à sua frente algumas notas de dinheiro e um cartão de crédito, associando, por meio da linguagem hipnótica (Erickson \& Rossi, 1979), ao primeiro a pesca cuidadosa, que exige paciência e estudo (a pesca com vara e molinete), e ao segundo a pesca massiva, sem critério e, por vezes, exagerada (a pesca por redes de arrastão). Fixando seu olhar nestes objetos, induziu-lhe ao transe no qual teceu as seguintes sugestões:

“E você pode aproveitar este momento aí em seu barco(...) esperando o peixe vir para desafiá-lo(...) e podem passar nuvens, encobrirem o sol( ...) e você espera, aproveitando essa bela paisagem( ...) e sua respiração muda, seu corpo se solta, porque você percebe que, para pescar, é melhor relaxar e ficar tranquilo(...) talvez até ceder linha para o peixe(...) como estratégia para cansá-lo(...) e por isso você lembra das pessoas que pescam pelo arrasto e pegam filhotes, mariscos, 
peixes jovens ( ...) tantas coisas desnecessárias(...) e pode se lamentar por elas...".

Tais sugestões trabalharam intensamente as temáticas de autoimagem. A aproximação e visualização da própria imagem no espelho, em transe, costuma ser uma das técnicas mais úteis e mobilizadoras do processo terapêutico (Haley, 1985), principalmente em pessoas que construíram, ao longo da vida, como no caso de Roberto, uma série de configurações de sentidos de menos valia e depreciação sobre si mesmas. No entanto, o objetivo da técnica não é apenas a mobilização emocional: é importante que seja criado um contexto de reconciliação consigo mesmo, de modo a promover novas possibilidades configuracionais para a auto-imagem. Desse modo, além da visualização, o terapeuta procedeu à criação de um contexto favorável, não só pelo acolhimento e pelas temáticas de valorização das conquistas, como no exemplo 2, como, neste trecho, pela aproximação visual de outros rostos significativos. Assim, ao chegar ao trecho de alguém que ele conhecia, mas para quem nem sempre olhava, o paciente logo visualizou sua própria imagem e o abraço em si mesmo foi um modo de concretizar um novo marco na relação consigo mesmo, o que acarretou mudanças muito significativas em sua vida cotidiana.

Curiosamente, na sequência das sessões, essa melhora o levou a uma série de mudanças configuracionais com relação ao dinheiro e seu uso, antes um tema ligado à obrigação de ajudar os outros em detrimento de si mesmo. Tais discussões clínicas foram marcadas pela emergência de sentimentos de revolta, quanto às relações de exploração de familiares, amigos, sócios e funcionários e suas constantes dificuldades econômicas, sentimentos estes que foram acolhidos e delimitados enquanto experiência para que Roberto pudesse canalizá-los (White, 2007) da melhor forma possível em seu cotidiano. Assim, compreendendo que o dinheiro deveria primeiramente servi-lo para depois, dentro de seu bom-senso, auxiliar os outros, o paciente apresentou diversas vezes uma postura de assertividade com relação ao tema, fosse quanto a cortar uma série de regalias de alguns parentes próximos, estabelecer um novo planejamento financeiro para si, fosse quanto a contratar uma consultoria que o auxiliasse a reestruturar as finanças de sua empresa.

\section{Discussões clínicas}

No que se refere às reflexões possíveis para um caso como o de Roberto, no qual o paciente está profundamente acometido por fortes dores crônicas, a relevância da hipnose está em larga medida associada ao vasto universo de processos inconscientes ou pré- 
reflexivos $^{5}$, isto é, além das deliberações racionais que compõem o mundo de experiências do sujeito. Nesse sentido, uma vez que a maior parte da vida psíquica é inconsciente (Erickson \& Rossi, 1979; Lakoff \& Johnson, 1999; Johnson, 2007) pode-se conceber que grande parte das configurações subjetivas das experiências de dores crônicas encontram-se nesse universo, não só no que diz respeito ao sofrimento corpóreo e vital (Merleau-Ponty, 2005), mas também às temáticas cotidianas que as perpassam como processo de subjetivação ligados à auto-imagem e sua riqueza cultural. Logo, a hipnose se apresenta como um recurso valioso não apenas de acesso a tais experiências de mundo, como também de busca de recursos e potencialidades aí existentes que se constituem como processos fundamentais de mudança que, geralmente, ficam inibidos ou inacessíveis ao sujeito em seus estados corriqueiros de vigília.

Tomando-se por base as sugestões aqui apresentadas em caráter ilustrativo, posto que na prática são muito mais amplas e complexas, é importante considerar que o efeito das mesmas é o da evocação de experiências do próprio mundo do sujeito, muitas das quais apresentavam-se isoladas e distantes de sua percepção consciente, como fundo de seu cenário. Parafraseando Sartre (2005) não se trata de um acesso a funções mentais especificas como imaginação e memória, mas a momentos de consciência, contextualizadas no tempo e no espaço vividos do sujeito. Assim, ao evocar as vivências infantis no rio, Roberto foi levado a esta experiência de mundo, com sua temporalidade própria de um passado que se presentificava ali e corria com muita leveza, e com uma espacialidade indissociada deste tempo e perpassada pelo lúdico, pela alegria, a socialização e os cuidados da mãe. Em semelhante processo o calor atuou como importante elemento material de seu imaginário (Bachelard, 2002), apresentando-se não apenas ligado ao prazer e relaxamento corporal (como o espichar-se ao Sol), como ainda a sensação de movimento e liberdade que tanto caracterizaram suas vivências infantis.

Desse modo, pode-se considerar que as estruturas amplas e abertas das sugestões indiretas são acompanhadas pelas vivências evocadas junto à corporeidade do próprio sujeito e que abarcaram diferentes níveis de configurações de suas dores crônicas. Do ponto de vista do esquema corporal, pode-se conceber que sugestões dessa natureza proporcionaram uma flexibilização de grande importância no que se refere à vivência do tempo e do espaço deste paciente, ou seja, duas referências centrais ligadas à sensação de aprisionamento imposta pela tirania de suas dores crônicas. A regressão ao passado vivido, no qual as coisas eram leves e alegres, e o tempo fluía sem o peso das preocupações, promoveu uma ruptura de grande importância na estagnação existencial em que o paciente se encontrava (Minkowski, 2005), como ainda no tempo quase paralisado, que parecia correr para ele de modo sofrido e arrastado em seu dia-a-dia. 
Simultaneamente, esse mesmo retorno a uma dimensão espacial na qual o corpo sentia o prazer da brincadeira e da natureza, de estar em grupo e ser cuidado, ofereceu a possibilidade de uma movimentação de caráter existencial, um espaço de pertencimento no qual era possível se mover com graça, alegria e liberdade, muito distinto do confinamento atual a que se via relegado.

O que chama a atenção nessas vivências é que elas não consistem na mera lembrança de fatos acontecidos, mas na evocação de experiências enraizadas no próprio corpo vivido, onde podem gerar sentido e criar realidades de mundo do sujeito. Em outras palavras, concebe-se que a hipnose não necessariamente adiciona elementos aos sistemas de configurações existentes, mas evoca-os de modo a colocá-los disponíveis ao sujeito (figura), principalmente em seu potencial de criação de novas possibilidades de postura e movimento. Ela parece desestabilizar ou perturbar tais sistemas, destacando suas capacidades de auto-poiésis ou auto-criação (Morin, 2001), de maneira a abrir diferentes e novas possibilidades de arranjo para o esquema corporal. Nesse sentido, uma vez que tais experiências de tempo e espaço vividos, como da materialidade imaginária (como no caso do suadouro), brotam de dentro para fora, torna-se possível considerar que, em alguma medida, é a partir da reconfiguração delas que ocorre uma flexibilização nada desprezível das linhas virtuais enrijecidas dos sistemas que compunham seu esquema corporal.

A forte conexão promovida pela hipnose, principalmente por meio da intensa emocionalidade (Sartre, 2009), com tais elementos de suas configurações distanciadas de seu cenário atual permite destacar mudanças muito significativas nesse nível de corporeidade.

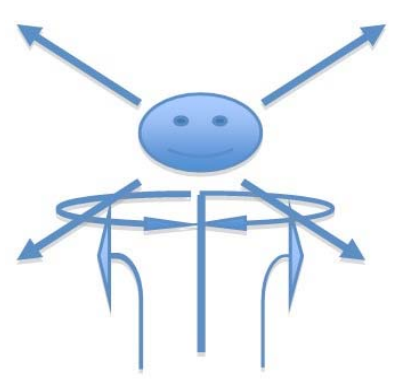

Figura 2 - Representação das linhas virtuais do esquema corporal do paciente após a terapia. Verifica-se que as setas circulares inferiores, que representam o campo de abrangência de movimento dos pés, e as setas circulares superiores, que representam o campo de movimento de ombros e braços, apresentam uma considerável ampliação, se comparadas à figura 1 . O aumento do campo entre ambos os conjuntos de setas circulares oferece um espectro maior para a movimentação e rotação da coluna, como mostram as setas laterais. As setas diagonais que saem da cabeça remetem a diversificação de movimentos para o pescoço e, consequentemente, para as possibilidades de foco visual. 
À princípio observa-se que Roberto passou a alargar em muito o espectro de rotação em torno de seu eixo vertical, de modo a poder inclinar sua coluna para os lados e para frente em ângulos muito mais amplos do que antes (fig. 2). Livre do contínuo receio de queda e das ameaças constantes de dor, seus pés passaram a se movimentar num campo mais amplo distanciando-se do eixo vertical, podendo virar para os lados, como ainda permitir movimentos como agachar-se e girar o corpo apoiando-se nos calcanhares. Essa flexibilidade também retornou ao caminhar, que voltava a apresentar a sincronia harmônica entre ombro e perna do lado oposto, de maneira a permitir uma fluidez de movimento que em muito surpreendeu o paciente e seus familiares.

Nesse sentido, é possível cogitar que tal flexibilização das linhas virtuais do esquema corporal proporcionaram novas e importantes produções de sentido para o sujeito em diferentes níveis. A possibilidade de mover-se novamente pelo mundo, de poder explorálo e experimentá-lo, de poder manter-se ereto e com amplo espectro de movimentos em torno do próprio corpo e de estabelecer relações mais horizontais com as pessoas podem ser concebidas em torno de dois significados centrais: autonomia e liberdade. Tanto em termos de um nível corpóreo e vital, como da consciência, autonomia e liberdade são características importantes para a existência e funcionamento dos sistemas humanos (Morin, 2001), como de sua posição no mundo. Em termos corpóreos e vitais, semelhantes características implicam para seus sistemas de esquema corporal na retomada de uma série de processos antes inibidos pela tirania da dor crônica: ângulos de movimentos, em termos concretos e virtuais, fluidez e leveza na execução, como ainda o prazer e a satisfação na realização dos mesmos. Embora não se cogite uma relação linear com - nível da consciência, tais conquistas acabam por trazer repercussões significativas e muito marcantes em termos deste nível, sobretudo no tocante à auto-imagem, posto que a satisfação sentida por Roberto na retomada destes esquemas contribuíram em muito com o trabalho desenvolvido em termos de um novo posicionamento diante de si e dos outros.

Uma análise muito semelhante seria possível no tocante aos sistemas dos esquemas corporais envolvendo cabeça, pescoço e ombros que, no entanto, contaram ainda com outra particularidade (fig. 2). O conjunto e a diversidade de imagens visuais (Sartre, 2005) evocados pelas sugestões envolveu uma estrutura considerável de recursos para a mudança do foco visual fixo apresentado pelo paciente. Associados aos processos descritos no parágrafo anterior, as visualizações apresentaram o reviver de cores, luzes, formas de objetos, pessoas, paisagens, sem contar a dimensão sensória e cinestésica que as acompanhavam, que contrastavam com a fixação 
do olhar ao qual Roberto se via constrangido pela dor crônica. Então, apesar de as dores nesta região ainda terem permanecido, a flexibilização das linhas do esquema em torno do pescoço e movimentos da cabeça, aliada à leveza que se instalou neste esquema, foi de grande importância para que o paciente pudesse retomar diversas ações de grande valia para sua subjetividade, como a interação com as pessoas, a fotografia, o prazer de apreciar uma paisagem e a condução de seu carro. Tornava-se-Ihe, assim, possível olhar as coisas do mundo e se direcionar a elas que ficaram, novamente, mais próximas de suas mãos e de seus interesses. $\mathrm{Na}$ mesma perspectiva, também é possível cogitar que o trabalho desenvolvido junto a este esquema cabeça, pescoço e ombros também contribuiu em larga medida para as reconfigurações da autoimagem, uma vez que a cabeça constitui-se como um dos momentos mais importantes desta dimensão (Haley, 1985), seja por ser uma parte do corpo culturalmente associada à razão e ao controle, seja por conta da própria face que desempenha um papel fundamental para a construção da auto-imagem.

Não foi sem razões que, em três meses de terapia, suas dores reduziram significativamente e Roberto pôde retomar atividades de grande interesse em seu cotidiano, como as longas caminhadas ( 8 $\mathrm{Km}$ ) em dias alternados da semana, as aulas de dança, as tarefas no pomar, no jardim, e no seu aviário, como ainda uma supervisão mais cuidadosa de diferentes procedimentos de sua empresa. No entanto, a não linearidade defendida por Merleau-Ponty (2005) e por autores contemporâneos (Gallagher \& Zahavi, 2008; Gonzalez Rey, 2007; Johnson, 2007) também pode ser verificada em razão do descompasso entre os resultados obtidos quanto ao esquema corporal, o que durou em torno de três meses, e a auto-imagem, cujas reconfigurações atingiram resultados mais estáveis com um ano de terapia. O caso de Roberto destaca uma necessidade particular que é também encontrada em grande número de pessoas para quem as demandas de um trabalho hipnótico não se esgotam com a reconfiguração dos sistemas que compõem o esquema corporal, uma vez que remetem a questões que perpassam a auto-imagem das mesmas, como o relacionamento social, a herança familiar, a reconciliação com suas raízes culturais, a ascensão social e, principalmente, a relação com o dinheiro. Tais processos costumam entrelaçar, numa rede complexa de produção de sentidos (Neubern, 2010b), temáticas do cotidiano e dos projetos existenciais do sujeito (Binswanger, 2008; Minkowski, 2005) e necessitam de trabalho terapêutico específico cujos efeitos, necessariamente, incidem nas experiências de dores crônicas.

Nesse sentido, além dos pontos já relacionados às mudanças do esquema corporal, as sugestões hipnóticas indiretas evocaram vivências de mundo, com espaço, tempo e materialidade vividos 
próprios de suas experiências em torno de temáticas centrais de sua auto-imagem. Tais intervenções, entretanto, não se limitaram a situá-las como figura em seu cenário, mas em redefini-las (Erickson \& Rossi, 1979) numa perspectiva terapêutica que pudesse auxiliá-lo na reconfiguração de sentidos em torno de semelhantes temáticas. Desse modo, é possível considerar que a hipnose evoque tais experiências dentro de princípios terapêuticos muito específicos. De inicio, as sugestões possuem um caráter aberto, mas também seletivo: elas colocam, subliminarmente, certas condições para as experiências que emergem, mas estas são selecionadas pelo próprio sujeito, frequentemente, de modo espontâneo ou pré-reflexivo (Merleau-Ponty, 2008). Ao mesmo tempo, elas são situadas numa perspectiva de redefinição para que o sujeito as enfoque dentro de uma dimensão terapêutica, que permita que ele se relacione consigo e com os outros de uma forma distinta da paralisação habitual imposta por todo um conjunto de processos já configurados na dor crônica, que envolve inclusive dimensões culturais e sociais. Essa forma de evocação permite que tais experiências possam assumir a posição de figura em seu cenário, rompendo com o negativismo até então típico de produção de sentidos sobre si mesmo, o que consiste em consideráveis ganhos em termos terapêuticos (Neubern, 2010b; White, 2007). Assim, ao evocar a figura do menino sertanejo e pobre, o paciente o visualizou nas cenas habituais de negociação comercial do sertão, na feira ou com outros sertanejos adultos; entretanto, essa criança não apareceu como uma vítima de violência dos pais ou da injustiça social, mas, pela própria forma das sugestões, como alguém que possuía esperteza e sabedoria, recursos e habilidades que muito Ihe auxiliaram em sua vida profissional e em sua ascensão social.

O retorno a um passado e um espaço presentificados no qual possuía tanta leveza e habilidades, proporcionou a Roberto o reconhecimento de quantos recursos preciosos ele trazia em si mesmo, de modo a semear diversas mensagens de valorização e estima por si mesmo. Por se referir a todo um nicho cultural, tais sugestões também implicavam mensagens de reconciliação com suas raízes, valorizando sua sabedoria e beleza, principalmente em termos de recursos para a superação de dificuldades. Semelhante apelo ocorria tanto pela materialidade evocada em suas experiências, em termos de luz, cor, som, calor, como de toda uma lógica de resolução de problemas e de reflexão filosófica sobre a vida que ficavam relegadas ao fundo de seu cenário em função de sua forte obediência à obrigação de ajudar a família e as demais pessoas. Concebe-se aqui que a emergência de semelhantes processos foi de grande valia para que o sujeito desenvolvesse novos sistemas de configurações nos quais os sentidos de vergonha não fossem mais os dominantes, sendo substituídos por outros de valorização, humor e prazer quanto a si e sua cultura. Não 
foi sem razões que Roberto, vez por outra, contava piadas sertanejas com alto teor de inteligência e, em certa ocasião, para surpreender um amigo deprimido, incorporou um personagem sertanejo (vestindo-se, falando, gesticulando e agindo como tal), causando uma agradável surpresa a todos.

Desse modo, as sugestões hipnóticas trouxeram à tona experiências e processos capazes de redefinir dois dos mais importantes eixos da constituição subjetiva do sujeito, a causalidade, isto é, como o sujeito explica as causas sobre o que lhe acontece, e às formas de relação com o outro (Ellenberger, 2004). Tanto a cena do abraço a si mesmo, como as sugestões relacionando pesca e dinheiro, contribuíram para que o paciente continuasse o desenvolvimento do processo de valorização de si de modo a abrir duas perspectivas importantes em seu processo terapêutico. Por um lado, não cabiam mais as acusações à sociedade ou à sua família sobre as injustiças que sofria; caberia a ele, Roberto, poder assumir as responsabilidades por sua vida e redefinir os projetos de sua existência. Por outro lado, como tais mudanças configuracionais quanto a si mesmo foram de grande impacto em seu mundo subjetivo, o paciente passou a assumir uma forma de relação muito diferenciada com relação aos outros. Não lhe caberia mais simplesmente assumir o prejuízo de muitas relações, que implicavam em vários tipos de ônus, inclusive quanto ao dinheiro, uma vez que seus interesses também eram importantes e ele não deixaria de colocá-los em pauta pelo mero dever de satisfazer os outros. A arena das relações sociais deixava, portanto, de se constituir como um cenário de servidão e exploração para se tornar um campo das negociações possíveis.

\section{Considerações finais}

A proposta de conceber a relação entre hipnose e dor crônica numa perspectiva fenomenológica rompe com a linearidade presente nas noções clássicas sobre o assunto, muito marcadas pela lógica estímulo - resposta ou pelo mecanicismo médico tradicional (Neubern, 2010a). Trata-se de uma proposta prática e exigente em termos teóricos que busca concebê-la como um processo humano e contextualizado numa relação perpassada por distintos registros que constituem a subjetividade de seus protagonistas. Assim sendo, quando se concebe que a hipnose traz à tona experiências de mundo, e não meramente funções mentais, perpassadas por importantes referenciais de espaço, tempo e materialidade vividos, abre-se a possibilidade de pensar a complexa rede de sistemas que formam o esquema corporal, como de processos humanos que são constituintes da imagem que as pessoas compõem frente a si mesmas e ao mundo. 
É certo que a composição de semelhantes sistemas, como alertam alguns autores (Gallagher \& Zahavi, 2008; Gonzalez Rey, 2007; Johnson, 2007; Lakoff \& Johnson, 1999) necessitam de uma aproximação maior quanto a ramos como as neurociências, as ciências cognitivas e importantes aportes contemporâneos, tanto pelos avanços na compreensão da experiência das dores crônicas (Jensen, 2010), como pelas próprias necessidades de aprofundamento das idéias de Merleau-Ponty (2005) e Sartre (2005), lançadas inicialmente a partir dos anos 30. Como os diferentes neurotransmissores, fibras musculares, secreções hormonais, junções ósseas e nervosas, dentre outros, poderiam compor tais sistemas, que consistem em questões que necessitam de maiores aprofundamentos. Entretanto, tal limitação não invalida a pertinência da proposta aqui levantada porque esta destaca como a virtualidade das linhas de força do esquema corporal ligado às dores crônicas, articulando partes do corpo vivido, podem ser alteradas por meio da hipnose, em importantes referenciais de como a própria pessoa vivencia seu tempo, seu espaço e a matéria que o constitui, sua forma de conceber a causa de sua situação e seus modos de relação com as pessoas.

Como diria Merleau-Ponty (2005), músculos, ossos, pele, órgãos e nervos articulam-se na harmonia de um movimento que em muito escapa à deliberação do sujeito, mas obedece a uma lógica fornecida por essa virtualidade que impede que esse movimento se perca na desordem de um espasmo. E isso, longe de se constituir como um processo mecânico, ocorre porque essa lógica remete à estruturação de comportamento dos seres vivos, que se dão nos cenários perpassados pelos referenciais acima citados, que faz com que os movimentos do esquema não se constituem como os de uma maquina isolada, mas de uma pessoa, em sua movimentação existencial pelo mundo. O que a hipnose parece desencadear nesse nível do esquema corporal são vivências embutidas nesses complexos sistemas que passam a compô-lo como figura e se tornam mais acessíveis ao sujeito, abrindo-Ihe a possibilidade de alterar e aliviar sua experiência de dor crônica. Assim, uma cena como a de Roberto na infância, brincando no rio, pode trazer à tona fortes experiências sensórias e motoras (como prazer, leveza e analgesia), fluidez temporal e uma relativa, mas valiosa, liberdade de movimento em diferentes perspectivas de espaço. Em outras palavras, a hipnose parece possuir algumas chaves de grande relevância para a abertura de importantes arquivos vividos embutidos na corporeidade dos sujeitos, que associam de modo irremediável, os movimentos aparentemente mecânicos e maquínicos do esquema corporal às experiências vividas de uma pessoa que o contextualizam e permitem seu trânsito pelo mundo. 
A não linearidade entre tais dimensões da corporeidade - o esquema corporal e a auto-imagem - traz ainda importantes contribuições para a compreensão da experiência de dor crônica, particularmente em função de sua dimensão sistêmica. Embora a dor pareça, até o momento atual das pesquisas, estar sempre presente em termos de esquema corporal, a pessoa que a configura nesta dimensão não necessariamente a configura em termos de auto-imagem. De igual modo, mudanças na auto-imagem não necessariamente implicam em modificações significativas em termos de esquema corporal. Isto porque, embora possam existir relações entre ambas dimensões, cada uma delas possui particularidades e sistemas que lhe são próprios e, em consequência, exigências de abordagem específicas para suas próprias configurações, o que remete a uma dimensão autônoma da organização de tais sistemas. Mesmo as relações entre tais dimensões não devem ser concebidas à priori pelo terapeuta, mas percebidas por meio de um olhar preciso clínico e qualitativo de pesquisa que privilegie o cenário de cada sujeito (Neubern, 2010b). Tal postura impede o pensamento reducionista muito comum em profissionais da clínica e da saúde que estabelece uma relação simplista, maniqueísta e linear entre dimensões como mente e corpo. Por outro lado, pode-se conceber que as experiências de dores crônicas sejam influenciadas pelo trabalho hipnótico da auto-imagem basicamente de duas formas. À princípio, ao envolver processos configuracionais de dor crônica integrados à auto-imagem da pessoa, como suas dimensões relacionais, familiares, culturais e sócioeconômicas, tal com ilustrado pelo caso de Roberto, a hipnose pode proporcionar modificações muito significativas de tais processos. Não raro a produção de sentidos, com toda sua carga de emocionalidade, como as pautas relacionais dessas dimensões levam a um agravamento intenso das dores crônicas, que muitas vezes é acompanhado por uma sensação imaginária de peso, soco, queimadura, facada, corte, puxões e espetadas. À medida que a hipnose auxilia o sujeito a se conectar com uma ordem diferente de experiências, a partir dos arquivos de seu próprio mundo vivido, e auxilia esse sujeito a redefinir as referências de tais experiências de mundo, como a causalidade e as relações com o outro (Ellenberger, 2004), a modificação dos modos de relação e subjetivação com tais dimensões torna-se uma possibilidade concreta. A valorização de si mesmo e a modificação da pauta de relações abusivas ou opressoras com pessoas ou sistemas de crença constituem-se em dois processos que comumente são associados, pelos próprios pacientes, a uma melhora de grande importância no bem estar, na qualidade de vida e na redução de suas dores. É possível mesmo afirmar que, em casos como o de Roberto, nos quais as dores crônicas também se configuram em termos de auto-imagem, se tais dimensões não são devidamente trabalhadas, as dores talvez possam reincidir, trazendo 
ao sujeito, novamente, uma considerável carga de sofrimento. Talvez seja este uma das zonas de sentido de maior importância, atualmente, para a abordagem da cronicidade, não só em termos de dores, mas também de um grande número de doenças que apontam para consideráveis dificuldades de profissionais e do próprios sistema de saúde que muitas vezes parecem não estar preparados para a lida cotidiana com as mesmas.

Por fim, a perspectiva das configurações de dores crônicas ligadas à auto-imagem remete a uma compreensão mais abrangente sobre tais experiências. A proposta de se conceber que tais dores também podem estar incrustadas na imagem que as pessoas fazem sobre si mesmas não remete apenas a exigências técnicas de abordagem, mas principalmente à necessidade de compreendê-las como constitutivas da vida cotidiana das pessoas, cujos cenários devem ser priorizados para o tratamento. Trata-se tanto de uma proposta na qual a dor seja contextualizada na vida da pessoa, onde gera sentidos subjetivos para suas relações e seu existir, como de uma proposta que situe a pessoa, e não uma entidade substancializada, como foco principal a ser abordado. Afinal, a atualidade cotidiana na clínica e na saúde tem mostrado, mais que nunca, a importância de que a pessoa, e não a doença, seja a figura das reflexões, esforços e interesses profissionais.

\section{Referências}

Bachelard, G. (2002) La psychanalyse du feu. 1.ed. Paris: Gallimard. Binswanger, L. (2008). De la psychothérapie. In: L. Binswanger. Introduction à l'analyse existentielle. pp. 119 - 147. Paris: Minuit.

Ellenberger, H. (2004). A clinical introduction to psychiatric phenomenology and existential analysis. In: R, May, E. Angel., $\mathrm{H}$. Ellenberger (org). Existence. pp. 92 - 124. New York: Aronson Book. Erickson, M.(1985). An introduction to the study and application of hypnosis in pain control. In: M. Erickson, M. Rossi, E. (org). Healing in hypnosis. pp. 217 - 278. New York: Irvington.

Erickson, M. \& Rossi, E. (1979). Hypnotherapy: an exploratory casebook. 1.ed. New York: Irvington.

Gallagher, S. (2005). How the body shapes the mind. 1.ed. New York: Clarendon Press (Oxford).

Gallagher, S. \& Zahavi, D. (2008). The phenomenological mind. 1.ed. New York: Routledge.

Gonzalez Rey, F. (2007). Psicoterapia, subjetividade e pósmodernidade. São Paulo: Thomsom.

Haley, J. (1985). Conversations with Milton H. Erickson, M.D. Changin Individuals. New York: Triangle Press. 
Jensen, M.\& Patterson, D. (2006). Hypnotic treatment of chronic pain. Journal of Behavioral Medecine, 29(1), 95-124.

J ensen, M. (2010). A neuropsychological model of pain: research and clinical implications. The J ournal of Pain, Chicago, 11(1), 2-12.

Johnson, M. (2007). The meaning of the body. Chicago: University of Chicago Press.

Lakoff, G \& Johnson, M. (1999). Phylosofy in the flash. New York: Basic Books.

Lakoff, G \& Johnson, M. (2003). Metaphors we live by. Chicago: University of Chicago Press.

Morin, E. (2010). La méthode V. L'I dentité humaine. Paris: Seuil.

Merleau-Ponty, M. (2005). La structure du comportement. 3.ed. Paris: Puf.

Merleau-Ponty, M. (2008). Phénoménologie de la perception. Paris: Gallimard.

Minkowski, E. (2005). Le temps vécu. 2. ed. Paris: Puf.

Neubern, M. (2009a). Psicologia, hipnose e subjetividade. Revisitando a história. Belo Horizonte: Diamante.

Neubern, M. (2009b). Hipnose, dor e subjetividade: considerações teóricas e clínicas. Estudos de Psicologia, 14(2), 303-310.

Neubern, M. (2009c). Hipnose e dor: proposta de metodologia clínica e qualitativa de estudo. PsicoUSF, 14(2), 201-209.

Neubern, M. (2010a). Hipnose e dor: origem e tradição clínicas. Estudos de Psicologia, 14(2), 105-111.

Neubern, M. (2010b). Psicoterapia, dor e complexidade: construindo o contexto terapêutico. Psicologia: Teoria \& Pesquisa, 26(3), 515-

523.

Sartre, J-P. (2005). L'I maginaire. Psychologie phénoménologique de l'imagination. 3.ed. Paris: Gallimard.

Sartre, J-P. (2009). Esquisse d'une théorie des émotions. 4. ed. Paris: Hermann.

Stengers, I. (2002). Hypnose: entre magie et science. Paris: Seuil.

White, M. (2007). Maps of narrative practice. 2.ed. New York: Norton $\&$ Company.

\section{Endereço para correspondência \\ Mauricio da Silva Neubern}

Campus Universitário Darcy Ribeiro, ICC Sul, Instituto de Psicologia (IP), Asa Norte, CEP 70910-900, Brasília - DF, Brasil.

Endereço eletrônico: mauricio.neubern@gmail.com

Recebido em: 02/04/2012

Reformulado em: 29/11/2013

Aceito para publicação em: 30/11/2013

Acompanhamento do processo editorial: Ana Maria Lopez Calvo de Feijoo 


\section{Notas}

* Professor Adjunto, Departamento de Psicologia Clínica (PCL), Instituto de Psicologia (IP), Universidade de Brasília (UnB).

${ }^{1}$ Configurações ou formas para Merleau-Ponty (2005) são sistemas que integram diferentes elementos da experiência vivida pelo sujeito e antecedem a formação de sentidos subjetivos específicos e singulares para os diferentes momentos de tal experiência.

2 Para Merleau-Ponty (2005) a experiência corpórea de uma pessoa deve ser concebida em três níveis: o corporal, o vital e o da consciência. Devido ao caráter sistêmico (configuracional) de suas organizações, tais níveis mantêm entre si certa autonomia, o que lhes permite uma relação não-linear. Interpenetram-se e se influenciam, mas não guardam entre si uma relação de justaposição.

${ }^{3} \mathrm{O}$ atendimento clinico do paciente aqui discutido ocorreu no contexto de uma pesquisa institucional do autor, aprovada pelo comitê de ética da Universidade de Brasília. Atesta-se que todas as exigências éticas foram cumpridas, principalmente a assinatura do termo de consentimento livre e esclarecido e o sigilo sobre sua identidade.

${ }^{4}$ A técnica da levitação de braço consiste numa forma de desencadear, de modo mais rápido, a emergência do estado de transe hipnótico. O terapeuta segura ou pede que o paciente erga suavemente seu braço sustentando-o no ar. Esse processo é acompanhado por um conjunto de sugestões ligadas às metas desta indução em específico.

${ }^{5}$ Talvez para evitar uma aproximação com a hegemonia psicanalítica, os autores clássicos da fenomenologia, como Sartre (2009) e Merleau-Ponty (2008), raramente utilizam o termo inconsciente. No entanto, a proposta de um mundo pré-reflexivo nestes autores assemelha-se, em muito, às noções de inconsciente de Erickson (1985) e de autores contemporâneos (Gallagher, 2005; Lakoff; Johnson, 1999).

Trabalho oriundo da pesquisa institucional do autor "Subjetividade, hipnose e dor crônica: construindo o contexto terapêutico". Este trabalho foi aprovado pelo comitê de ética da UnB e obedeceu rigorosamente a todos os cuidados éticos de pesquisa com seres humanos. Agradecimentos ao Departamento de Pós-Graduação e Pesquisa (DPP) e ao CAEP (Centro de Atendimentos e Estudos Psicológicos, IP/UnB). 